\title{
The Effects of Ghrelin on Energy Balance and Psychomotor Activity in a Goldfish Model: An Overview
}

\author{
Ki Sung Kang, Satowa Yahashi, and Kouhei Matsuda \\ Laboratory of Regulatory Biology, Graduate School of Science and Engineering, University of Toyama, 3190-Gofuku, \\ Toyama 930-8555, Japan \\ Correspondence should be addressed to Kouhei Matsuda,kmatsuda@sci.u-toyama.ac.jp
}

Received 2 March 2011; Accepted 22 March 2011

Academic Editor: Jean-Marie Zajac

Copyright ( $) 2011 \mathrm{Ki}$ Sung Kang et al. This is an open access article distributed under the Creative Commons Attribution License, which permits unrestricted use, distribution, and reproduction in any medium, provided the original work is properly cited.

The goldfish (Carassius auratus) has a number of merits as a laboratory animal, and we have extensively identified the mechanisms by which ghrelin regulates food intake in this species. For the first time, we have purified and characterized 11 molecular variants of ghrelin that are present in goldfish intestine and shown that 17 -residue ghrelin, the predominant form with $n$-octanoyl modification, is biologically active and implicated in the regulation of food intake as an endogenous orexigenic factor. Ghrelin and its receptor system are present not only in peripheral tissues such as stomach and intestine, but also in the central nervous system. Recent studies have also revealed that a number of neuropeptides are widely distributed in the brain in key areas of emotional regulation, and their role as modulators of behavioral states is being increasingly recognized. Interestingly, administration of ghrelin induces an orexigenic effect and also modifies locomotor activity, suggesting the involvement of ghrelin in feeding control and regulation of energy balance. Information derived from studies of ghrelin has been increasing, and important results have been obtained from both fish and mammals. Here, we present an overview of the effects of ghrelin on energy balance and psychomotor activity in the goldfish as an animal model. The available data provide an insight into evolutionary background of ghrelin's multiple actions on energy homeostasis in vertebrates.

\section{Introduction}

The goldfish (Carassius auratus) has been employed as a useful laboratory animal in the fields of cell biology, immunology, endocrinology, molecular evolution and comparative genomics, neurobiology, and learning and memory [1-7]. The goldfish has several merits as a laboratory animal. Under experimental conditions, goldfish can be entrained to feed at a specific time of day on a diet sufficient to maintain a high body growth rate and have a constant daily food intake [8]. The basic mechanisms responsible for control of feeding behavior are conserved across vertebrates from fish to mammals [9]. Food intake in the goldfish can be measured by directly observing and recording the number of food pellets eaten by an individual fish [8]. Peptides or peptide analogs can be easily injected into the third ventricle of the brain, thus providing highly valuable information on feeding behavior [10]. We and others have extensively identified the regulatory mechanisms mediated by neuropeptides, such as that of ghrelin on food intake, using goldfish models [3, 10-15]. For example, acyl ghrelin, neuropeptide Y (NPY), and orexinA exert orexigenic effects, while corticotropin-releasing hormone $(\mathrm{CRH}), \alpha$-melanocyte-stimulating hormone $(\alpha-$ $\mathrm{MSH}$ ), and cholecystokinin (CCK) suppress appetite in this species (reviewed in [15]).

Ghrelin, a 28-amino-acid residue peptide that was first isolated from rat and human stomachs, acts as an endogenous ligand for the growth hormone secretagogues (GHSs) receptor. GHSs act at the GHS receptor to stimulate the release of growth hormone $(\mathrm{GH})$ in mammals as well as fish $[10,16-21]$. The GHS receptor is a member of the $G$ protein-coupled receptor superfamily with seven transmembrane domains [22]. Ghrelin possesses an $n$-octanoic acid modification at the third $\mathrm{N}$-terminal serine residue, which is essential for its biological activity in mammals [17]. The primary structure of ghrelin has been determined not only in mammals, but also in teleost fish species including the goldfish, Japanese eel (Anguilla japonica), rainbow trout 
(Oncorhynchus mykiss), tilapia (Oreochromis mossambicus), and channel catfish (Ictalurus punctatus) [18, 19, 23-27]. The fish ghrelins that have been characterized so far possess an amidated C-terminus, except for channel catfish ghrelin, which has 23 amino acid residues with a free terminus $[18,19,25,26]$. However, the structure of goldfish ghrelin used in earlier studies was deduced from its precursor cDNA sequence, and the native form of goldfish ghrelin had yet to be identified in the goldfish itself. In several species including humans and fish, the existence of ghrelin with different fatty acid modifications has been reported [18, 19, 25, 26, 28]. For the first time, we have purified and characterized 11 molecular variants of ghrelin that are present in goldfish intestine and shown that 17-residue ghrelin, the predominant form with an n-octanoyl modification, is biologically active and implicated in the regulation of food intake as an endogenous orexigenic factor in this species [27]. The Cterminus of almost all the goldfish ghrelin isolated was not amidated although other teleost ghrelins identified so far have the amide structure at the C-terminus as described above $[18,19,25,26]$.

Ghrelin mRNA is particularly abundant in the stomach and intestine and is also expressed at low levels in other organs, notably the brain (mainly the diencephalon), pituitary, heart, lung, pancreas, kidney, and placenta [17, 29-31]. The GHS receptor is also present in the brain, pituitary, gastrointestinal tract, kidney, pancreas, and heart $[22,32]$. Ghrelin is now considered to be a multifunctional peptide involved in the regulation of food intake and energy homeostasis in mammals and nonmammalian vertebrates $[26,33]$.

\section{Effect of Ghrelin on Energy Balance in Goldfish}

The regulation of energy balance is related to somatic growth and instinctive behavior, including feeding, reproduction, and emotion, and is a complex phenomenon involving interaction of the central and peripheral nervous systems, neuroendocrine system and gastrointestinal system [34, 35]. The hypothalamic region of the brain plays an important role in the regulation of feeding and neuroendocrine functions [36]. Many types of neurons in the hypothalamus and related regions express neuropeptides, such as ghrelin [17], orexin [37], NPY [38], agouti-related peptide (AGRP) [36], melanin-concentrating hormone (MCH) [39], proopiomelanocortin-derived peptides [40], pituitary adenylate cyclase-activating polypeptide (PACAP) [41, 42], CRH [43], neuromedin U (NMU) [44], and diazepambinding inhibitor- (DBI-) derived peptides [45, 46], which have all been implicated in the regulation of feeding behavior and also energy homeostasis in mammals.

Ghrelin plays an important role in energy balance by regulating food intake, body weight, and glucose homeostasis [47-49]. We have isolated the native form of goldfish ghrelin from the intestine [27], and it has been shown that intracerebroventricular (ICV) and intraperitoneal (IP) injection of goldfish ghrelin with an $n$-octanoic acid (acyl)

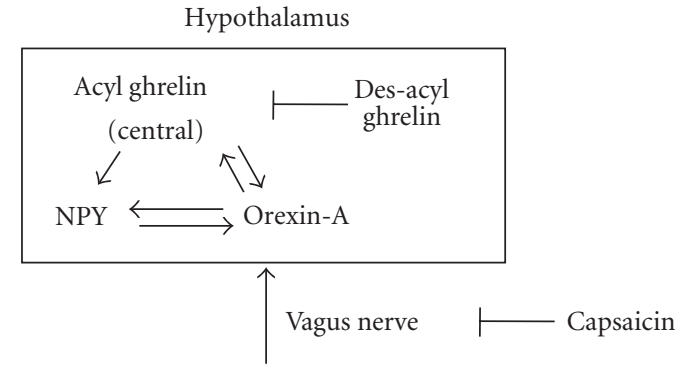

Gastrointestinal tract

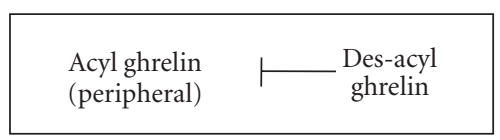

FIGURE 1: Schematic drawing of the orexigenic signaling pathways mediated by ghrelin in the peripheral and central nervous system in the goldfish.

moiety at the third serine residue stimulates food intake as well as the release of $\mathrm{GH}$ and gonadotropins from the pituitary gland $[10,27]$. The orexigenic action of ghrelin is blocked by treatment with NPY Y1 receptor and orexin receptor-1 antagonists in goldfish $[50,51]$, suggesting that this action is mediated by the NPY Y1 receptor- and orexin receptor-1-signaling pathways. Our previous data have also indicated that in goldfish, ICV injection of $\mathrm{MCH}$ inhibits food intake and decreases the expression of mRNA for ghrelin in the hypothalamus [52], suggesting that ghrelin and $\mathrm{MCH}$ functionally interact or exhibit mutual inhibitory effect to regulate feeding behavior in teleost fish. In contrast, ICV and IP administration of des- $n$-octanoylated (des-acyl) ghrelin produces no changes in orexigenic activity in goldfish $[13,14]$. This had been interpreted to indicate that des-acyl ghrelin has no effect on food intake. Surprisingly, however, the ICV and IP injection of des-acyl ghrelin at doses 310 times higher than that of acyl ghrelin was later shown to suppress the orexigenic action of ICV- and IP-injected acyl ghrelin, suggesting that des-acyl ghrelin functionally inhibits acyl ghrelin-induced orexigenic activity in goldfish [13]. A recent study has also revealed that similarly, des-acyl ghrelin suppresses acyl ghrelin-induced appetite in rats [53], suggesting that des-acyl ghrelin is involved in the regulation of appetite in vertebrates [35] (Figure 1). The vagus nerve has primary neuroanatomic roles in the gut-brain axis, transmitting meal-related signals elicited by contact of nutrient with the gastrointestinal tract to sites in the central nervous system that mediate ingestive behavior [54]. We previously examined the effect of capsaicin, a neurotoxin which destroys vagal afferents, on the orexigenic activity induced by IP injected acyl ghrelin [13]. Pretreatment with IP-injected capsaicin cancelled the orexigenic action of IPinjected acyl ghrelin in goldfish (Figure 1).

Recently, it has been demonstrated that ghrelin plays an important role in the regulation of central and peripheral lipid metabolism through specific control of hypothalamic AMP-activated protein kinase (AMPK), a critical metabolic regulator of both cellular and whole-body energy homeostasis $[55,56]$. We have conducted IP injection of ghrelin for 21 

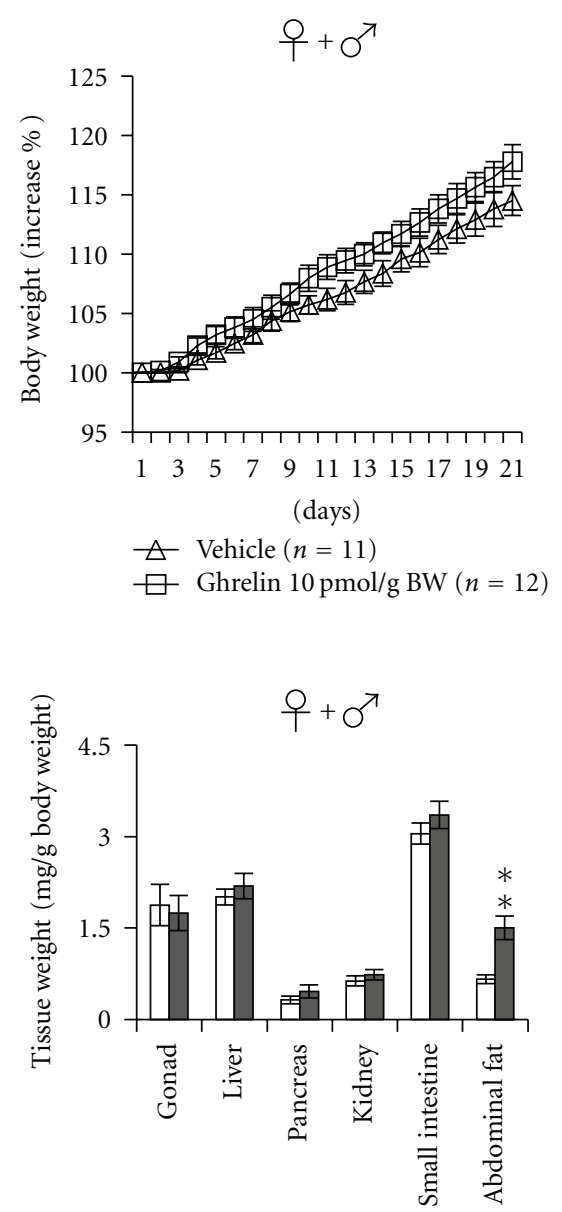

Vehicle $(n=11)$

Ghrelin $10 \mathrm{pmol} / \mathrm{g} \mathrm{BW}(n=12)$
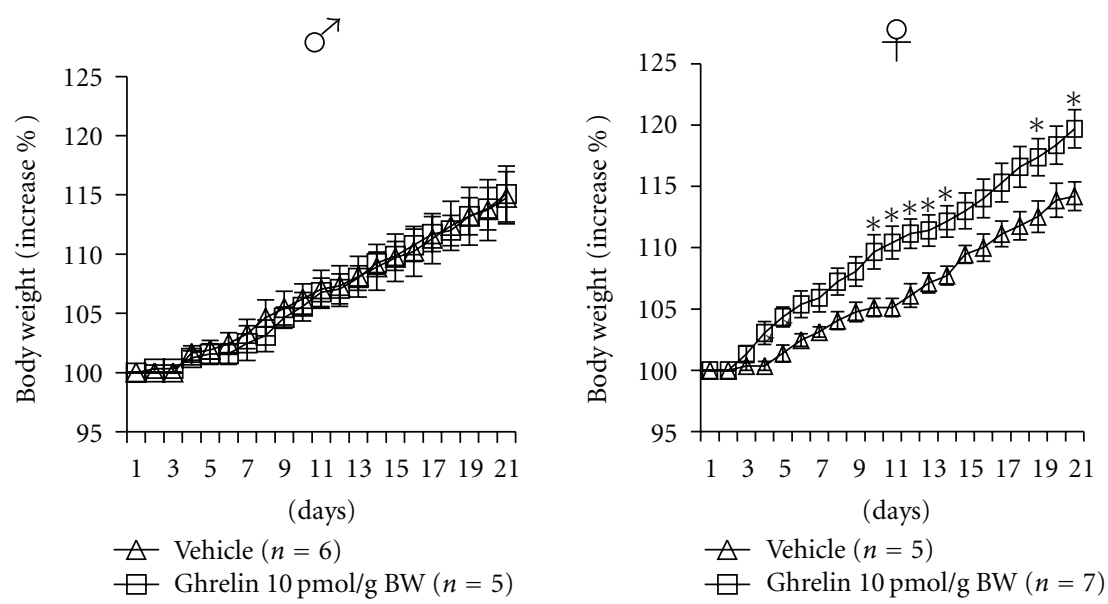

(a)
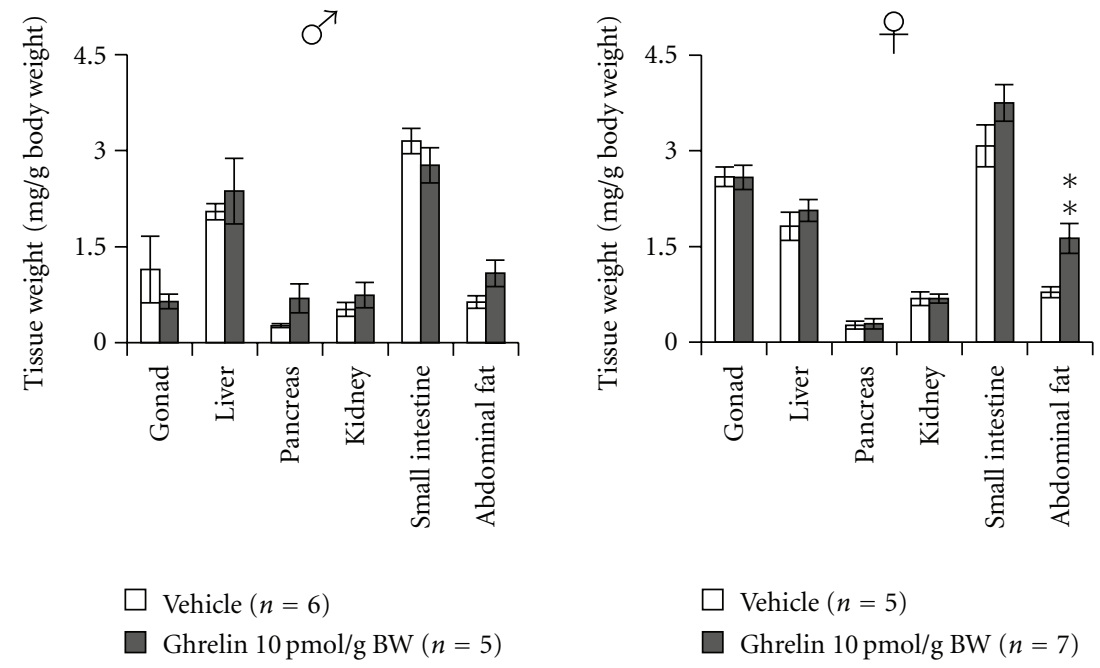

(b)

FIGURE 2: Effect of long-term IP injection of ghrelin on body and organ weights. Panel (a) shows the changes in body weight of goldfish during the experimental period. Panel (b) shows the changes in organ weight of goldfish after 21 consecutive days of IP ghrelin injection. Each column and bar represent the mean and S.E.M., respectively, and the numbers in parentheses in the legend indicate the number of fish used in each group. The significance of differences at each time point, compared to the vehicle-injected group, was evaluated by one-way ANOVA with Bonferroni's method $\left({ }^{*} P<.05,{ }^{* *} P<.01\right)$.

consecutive days to identify its long-term effects on growth and lipid metabolism in goldfish. The average body weight of goldfish (both sexes) increased gradually in the vehicletreated group but increased slightly after ghrelin $(10 \mathrm{pmol} / \mathrm{g}$ BW) cotreatment. However, when body weight was examined according to sex, female goldfish showed a significant increase of body weight after ghrelin cotreatment, whereas male goldfish showed no change (Figure 2(a)). Interestingly, a comparison of tissue weights (gonad, liver, pancreas, kidney, small intestine, and abdominal fat) showed that the amount of abdominal fat in female goldfish was significantly increased after 21 consecutive days of ghrelin treatment (Figure 2(b)). The level of lipid deposition in liver tissue of female goldfish was also significantly increased after IP injection of ghrelin for 21 consecutive days [34], in line with the observation that ghrelin induces abdominal obesity via lipid retention in rats [57]. Therefore, there is a sex difference in the effect of ghrelin on lipid metabolism in goldfish although the mechanism involved is still unknown. As ghrelin induces hepatic steatosis, increasing the number of lipid droplets and the content of triacylglycerol through a GHS receptor-dependent mechanism in rats [57], the lipid accumulation in goldfish may also mediated via a $\mathrm{GH}$ and its receptor-related pathways.

\section{Effect of Ghrelin on Psychomotor Activity in the Goldfish}

Recent studies have revealed that neuropeptides are widely distributed in the brain in key areas of emotional regulation 


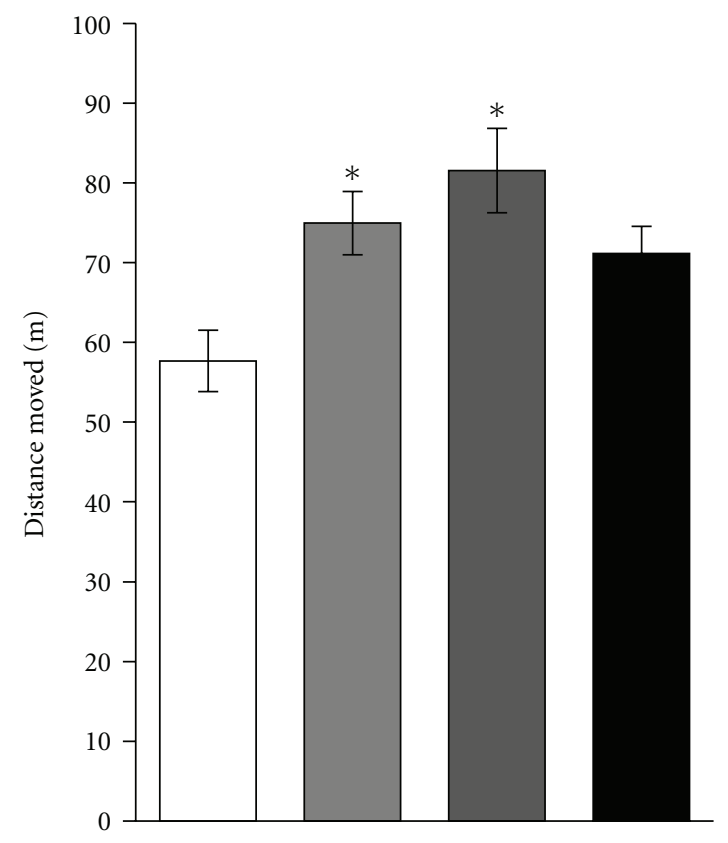

Vehicle $(n=11)$

Ghrelin $0.5 \mathrm{pmol} / \mathrm{g}$ BW $(n=16)$

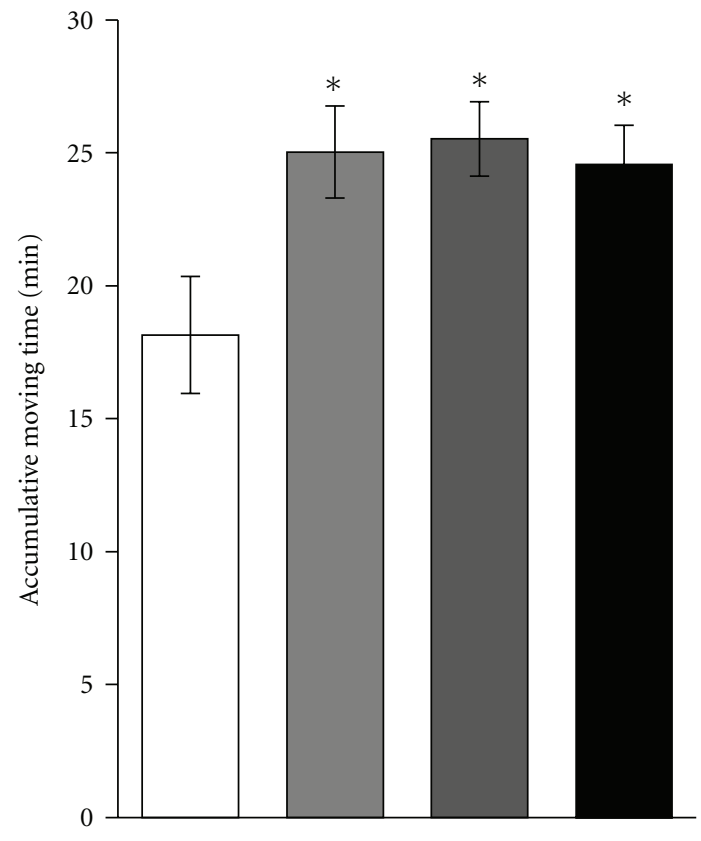

Ghrelin $1 \mathrm{pmol} / \mathrm{g}$ BW $(n=13)$

Ghrelin $2 \mathrm{pmol} / \mathrm{g}$ BW $(n=14)$

(a)
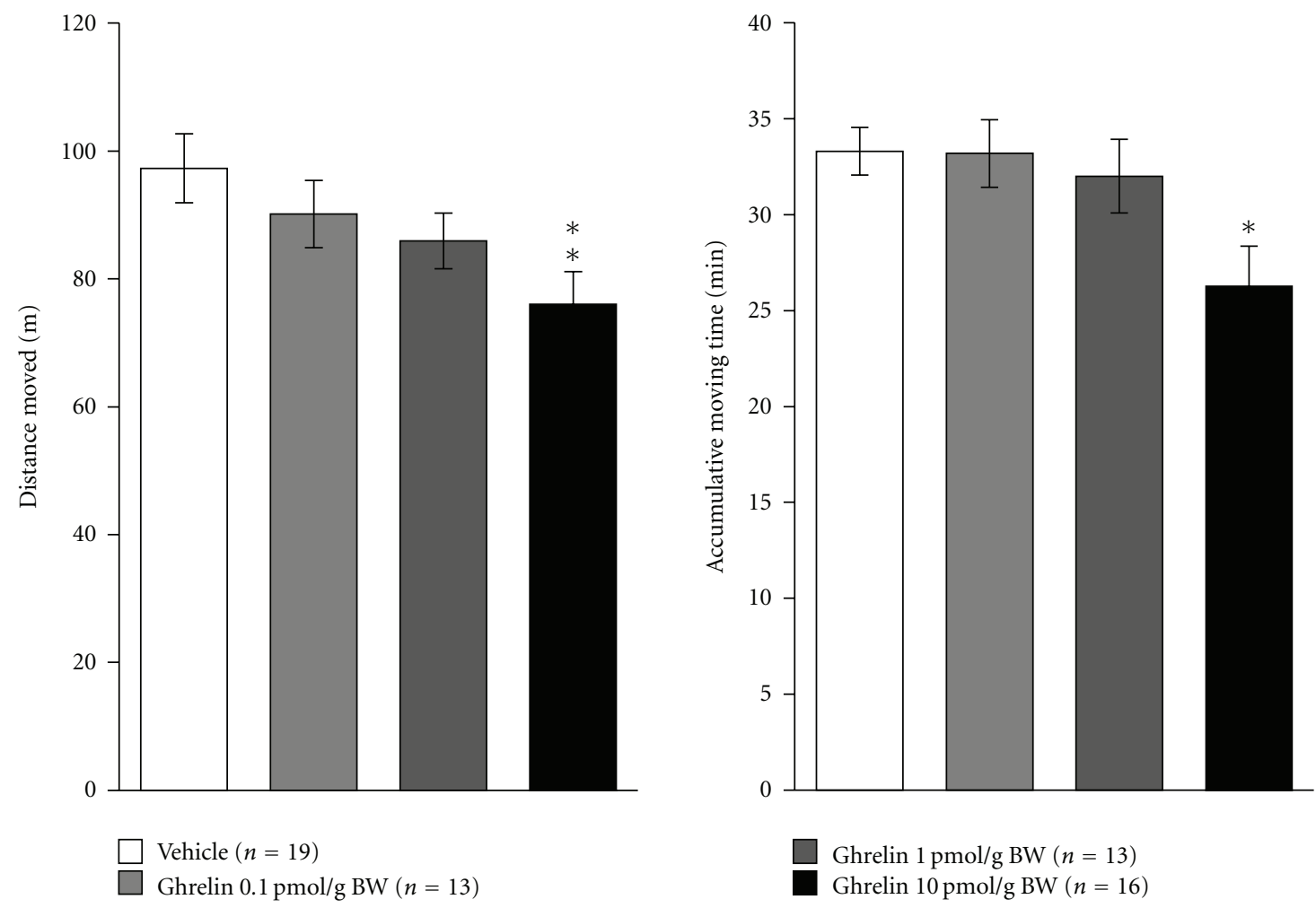

(b)

FIGURE 3: Effect of ghrelin on locomotor activity in goldfish. Panel (a) shows the effect of a single ICV injection of ghrelin on locomotor activity. Panel (b) shows the effect of IP-injected ghrelin on locomotor activity. The open field test, which started 15 min after ICV or IP injection and lasted $45 \mathrm{~min}$, was performed with a video tracking system for automatic recording of goldfish behavior (EthoVision Pro, Noldus Information Technology, Wageningen, Netherlands). Each column and bar represent the mean and S.E.M., respectively, and the numbers in parentheses in the legend indicate the number of fish used in each group. The significance of differences at each time point, compared to the vehicle-injected group, was evaluated by one-way ANOVA with Bonferroni's method $\left({ }^{*} P<.05,{ }^{* *} P<.01\right)$. 

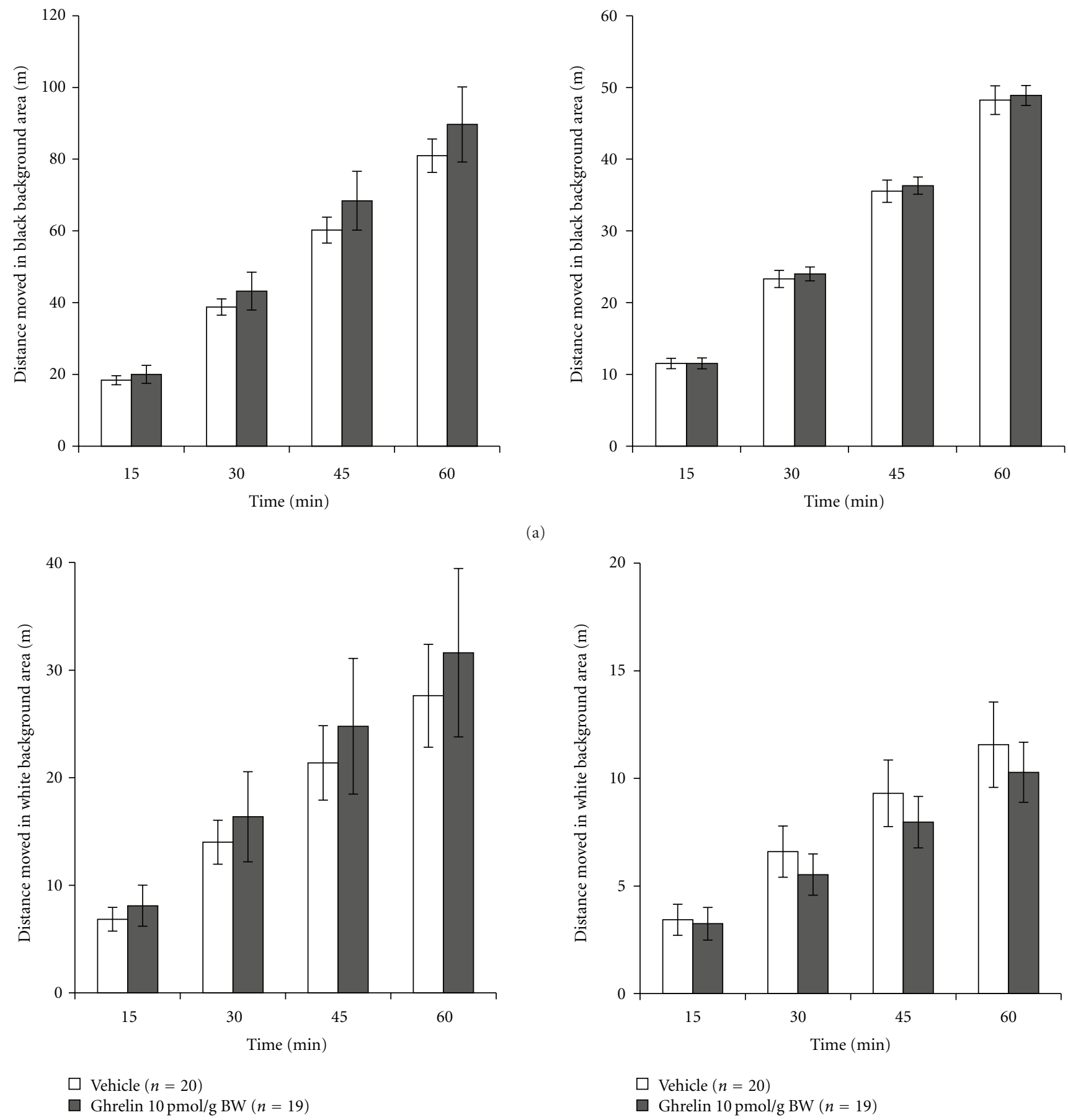

(b)

FIGURE 4: Effect of a single IP injection of ghrelin on black/white background preference in goldfish. Panel (a) shows the effect of ghrelin on the distance moved and latency period of goldfish in the black background area. Panel (b) shows the effect of ghrelin on the distance moved and latency period of goldfish in the white background area. Each column and bar represent the mean and S.E.M., respectively, and the numbers in parentheses in the legend indicate the number of fish used in each group. The data were evaluated by one-way ANOVA with Bonferroni's method.

and are being increasingly recognized as modulators of ehavioral states $[34,58,59]$. In rodents, psychomotor activity and/or emotional behavior are affected by neuropeptides involved in the regulation of feeding, such as ghrelin, orexin,
NPY, MCH, $\alpha$-MSH, PACAP, CRH, NMU, 26RFamide, and DBI-derived peptides, suggesting that these neuropeptides play psychophysiological roles, including regulation of feeding and emotion [59-63]. Recent advances in analytical 
technology and increased interest in fish behavior have revealed that several of these neuropeptides also influence the locomotor or psychomotor activity of teleost fish $[34,58]$.

Low physical activity levels are a major determinant of body fat gain during overfeeding [64]. Locomotion is a form of animal behavior necessary for seeking food, shelter and mates, interaction with competitors, and avoidance of predators [65]. In animal models, locomotor activity is one behavioral measure commonly used to study the level of not only physical activity but also anxiety [66-68]. TangChristensen et al. [67] showed for the first time that central administration of ghrelin decreases spontaneous locomotor activity in rats, whereas peripheral ghrelin injections is known to increase locomotor activity of rats [69]. In our study of goldfish [14], ICV injection of ghrelin increased locomotor activity, whereas IP injection of ghrelin at a dose 5 times higher than that used for ICV injection decreased locomotor activity (Figure 3 ). These results suggest that the central and peripheral actions of ghrelin are involved in the control of psychophysiological functions in rodents as well as in teleost fish although the mechanisms responsible for its different actions among the same or different species are still unclear. Plausible mechanistic pathways have been suggested by studies using rodent models. Ghrelin may mediate locomotor activity via noradrenergic pathways through the interaction with orexin. Dopamine has been implicated in the regulation of appetite and body weight $[70,71]$ and is certainly important for the central nervous control of motor activity $[72,73]$. Involvement of the ventral tegmental area dopaminergic system in orexin-induced activity has been demonstrated [74]. In addition, ghrelin-immunoreactive axonal terminals make direct synaptic contacts with orexinproducing neurons [75], and the orexinergic system is anatomically well placed to influence the arousal, motivational, metabolic, autonomic, and motor processes necessary for elicitting homeostatically appropriate behavior [68]. Therefore, the regulation of locomotor activity by ghrelin in goldfish may also be mediated through interaction with orexin.

The scototaxis protocol, a white/black background areas preference test, has recently been employed to investigate the psychomotor activity of fish, notably anxiety-like behavior $[76,77]$. In our study with goldfish, intact fish were found to prefer the black to the white background area: the average time spent in the black background compartment was 3 times greater than that in the white background area. This scototaxis test appears to be suitable for evaluating the effect of pharmacological compounds on psychomotor activity in fish $[34,58]$. In our experiment involving IP injection of ghrelin in goldfish, there were no significant changes in the time or locomotor activity in the black and white background areas (Figures $4(\mathrm{a})$ and $4(\mathrm{~b})$ ). These results suggest that ghrelin has no effect on anxiety in goldfish. However, several rodent studies have suggested that ghrelin mediates some of the usual behavioral responses to acute and chronic stress [78]. Gastric ghrelin mRNA or total plasma ghrelin increases in response to various forms of acute stress in mouse and rat models $[79,80]$. However, another group has demonstrated that ICV administration of ghrelin into the hippocampus, amygdala, or dorsal raphe nucleus induces anxiety-like behaviors in certain rat strains [81]. The reasons for the varied anxiety-related behavioral responses elicited by ghrelin are currently unclear, but differences in experimental conditions, strains, or species have been suggested [78]. Ghrelin-induced orexigenic action is mediated by the NPY Y1 or Y5 receptor-signaling pathway as described above. Recent studies have revealed that NPY also exerts an anxiogenic action via the NPY Y2 or Y4 receptor system [82-86]. It can also be speculated that ICV-injected ghrelin induces anxiety through the NPY Y4 receptor-signaling pathway.

\section{Conclusion and Perspectives}

The goldfish provides an excellent and widely used animal model for studying the neuroendocrine control of feeding behavior $[3,15,34]$. For nonmammals, such as teleost fish, information derived from studies of ghrelin has been increasing, and important results have been obtained. The most significant scientific advances in this respect are largely related to neuroendocrine signaling for regulation of growth, feeding, and psychophysiological behavior $[15,34,35]$. In this paper, we have summarized the effects of ghrelin on energy balance and psychomotor activity in the goldfish and shown that ghrelin plays an important role in energy balance in this species by regulating food intake, lipid metabolism, and also locomotor activity. The findings so far suggest that ghrelin plays a pleiotropic role in the regulations of energy homeostasis in fish through a mechanism similar to that in mammals although some of its actions differ among the same and different species.

\section{Acknowledgment}

This study was supported by a Grant-in-Aid from the Japan Society for the Promotion of Science (no.21370025 to K. Matsuda) and research grants from the University of Toyama (K. Matsuda) and the Mishima Kaiun Memorial Foundation (K. Matsuda).

\section{References}

[1] N. J. Bernier, X. Lin, and R. E. Peter, "Differential expression of corticotropin-releasing factor (CRF) and urotensin I precursor genes, and evidence of CRF gene expression regulated by cortisol in goldfish brain," General and Comparative Endocrinology, vol. 116, no. 3, pp. 461-477, 1999.

[2] S. Bretaud, P. Saglio, C. Saligaut, and B. Auperin, "Biochemical and behavioral effects of carbofuran in goldfish (Carassius auratus)," Environmental Toxicology and Chemistry, vol. 21, no. 1, pp. 175-181, 2002.

[3] H. Volkoff, A. J. Eykelbosh, and R. Ector Peter, "Role of leptin in the control of feeding of goldfish Carassius auratus: interactions with cholecystokinin, neuropeptide $\mathrm{Y}$ and orexin $\mathrm{A}$, and modulation by fasting," Brain Research, vol. 972, no. 1-2, pp. 90-109, 2003.

[4] P. C. Hanington, D. R. Barreda, and M. Belosevic, "A novel hematopoietic granulin induces proliferation of goldfish (Carassius auratus L.) macrophages," Journal of Biological Chemistry, vol. 281, no. 15, pp. 9963-9970, 2006. 
[5] J. Lou, M. Lang, W. Salzburger, N. Siegel, K. N. Stölting, and A. Meyer, "A BAC library for the goldfish Carassius auratus auratus (Cyprinidae, Cypriniformes)," Journal of Experimental Zoology Part B, vol. 306, no. 6, pp. 567-574, 2006.

[6] T. Preuss, P. E. Osei-Bonsu, S. A. Weiss, C. Wang, and D. S. Faber, "Neural representation of object approach in a decision-making motor circuit," Journal of Neuroscience, vol. 26, no. 13, pp. 3454-3464, 2006.

[7] J. T. Popesku, C. J. Martyniuk, J. Mennigen et al., "The goldfish (Carassius auratus) as a model for neuroendocrine signaling," Molecular and Cellular Endocrinology, vol. 293, no. 1-2, pp. 4356, 2008.

[8] B. A. Himick, Bombesin and cholecystokinin regulate feeding behavior and anterior pituitary hormone release in goldfish, Ph.D. thesis, University of Alberta, 1994.

[9] H. Volkoff and R. E. Peter, "Feeding behavior of fish and its control," Zebrafish, vol. 3, no. 2, pp. 131-140, 2006.

[10] H. Volkoff, L. F. Canosa, S. Unniappan et al., "Neuropeptides and the control of food intake in fish," General and Comparative Endocrinology, vol. 142, no. 1-2, pp. 3-19, 2005.

[11] N. De Pedro, A. L. Alonso-Gomez, B. Gancedo, M. J. Delgado, and M. Alonso-Bedate, "Role of corticotropin-releasing factor (CRF) as a food intake regulator in goldfish," Physiology and Behavior, vol. 53, no. 3, pp. 517-520, 1993.

[12] N. J. Bernier and R. E. Peter, "The hypothalamic-pituitaryinterrenal axis and the control of food intake in teleost fish," Comparative Biochemistry and Physiology B, vol. 129, no. 2-3, pp. 639-644, 2001.

[13] K. Matsuda, T. Miura, H. Kaiya et al., "Regulation of food intake by acyl and des-acyl ghrelins in the goldfish," Peptides, vol. 27, no. 9, pp. 2321-2325, 2006.

[14] K. Matsuda, T. Miura, H. Kaiya et al., "Stimulatory effect of n-octanoylated ghrelin on locomotor activity in the goldfish, Carassius auratus," Peptides, vol. 27, no. 6, pp. 1335-1340, 2006.

[15] K. Matsuda, "Recent advances in the regulation of feeding behavior by neuropeptides in fish," Annals of the New York Academy of Sciences, vol. 1163, pp. 241-250, 2009.

[16] C. Y. Bowers, F. A. Momany, G. A. Reynolds, and A. Hong, "On the in vitro and in vivo activity of a new synthetic hexapeptide that acts on the pituitary to specifically release growth hormone," Endocrinology, vol. 114, no. 5, pp. 1537-1545, 1984.

[17] M. Kojima, H. Hosoda, Y. Date, M. Nakazato, H. Matsuo, and K. Kangawa, "Ghrelin is a growth-hormone-releasing acylated peptide from stomach," Nature, vol. 402, no. 6762, pp. 656660, 1999.

[18] H. Kaiya, M. Kojima, H. Hosoda et al., "Amidated fish ghrelin: purification, cDNA cloning in the Japanese eel and its biological activity," Journal of Endocrinology, vol. 176, no. 3, pp. 415423, 2003

[19] H. Kaiya, M. Kojima, H. Hosoda et al., "Peptide purification, cDNA and genomic DNA cloning, and functional characterization of ghrelin in rainbow trout," Endocrinology, vol. 144, no. 12, pp. 5215-5226, 2003.

[20] L. G. Riley, T. Hirano, and E. G. Grau, "Rat ghrelin stimulates growth hormone and prolactin release in the tilapia, Oreochromis mossambicus," Zoological Science, vol. 19, no. 7, pp. 797-800, 2002.

[21] S. Unniappan and R. E. Peter, "In vitro and in vivo effects of ghrelin on luteinizing hormone and growth hormone release in goldfish," American Journal of Physiology, vol. 286, no. 6, pp. R1093-R1101, 2004.

[22] A. D. Howard, S. D. Feighner, D. F. Cully et al., "A receptor in pituitary and hypothalamus that functions in growth hormone release," Science, vol. 273, no. 5277, pp. 974-977, 1996.

[23] S. Unniappan, X. Lin, L. Cervini et al., "Goldfish ghrelin: molecular characterization of the complementary deoxyribonucleic acid, partial gene structure and evidence for its stimulatory role in food intake," Endocrinology, vol. 143, no. 10, pp. 4143-4146, 2002.

[24] I. S. Parhar, H. Sato, and Y. Sakuma, "Ghrelin gene in cichlid fish is modulated by sex and development," Biochemical and Biophysical Research Communications, vol. 305, no. 1, pp. 169175, 2003.

[25] H. Kaiya, B. C. Small, A. L. Bilodeau et al., "Purification, cDNA cloning, and characterization of ghrelin in channel catfish, Ictalurus punctatus," General and Comparative Endocrinology, vol. 143, no. 3, pp. 201-210, 2005.

[26] H. Kaiya, M. Miyazato, K. Kangawa, R. E. Peter, and S. Unniappan, "Ghrelin: a multifunctional hormone in non-mammalian vertebrates," Comparative Biochemistry and Physiology A, vol. 149, no. 2, pp. 109-128, 2008.

[27] T. Miura, K. Maruyama, H. Kaiya et al., "Purification and properties of ghrelin from the intestine of the goldfish, Carassius auratus," Peptides, vol. 30, no. 4, pp. 758-765, 2009.

[28] H. Hosoda, M. Kojima, T. Mizushima, S. Shimizu, and K. Kangawa, "Structural divergence of human ghrelin: identification of multiple ghrelin-derived molecules produced by posttranslational processing," Journal of Biological Chemistry, vol. 278, no. 1, pp. 64-70, 2003.

[29] K. Mori, A. Yoshimoto, K. Takaya et al., "Kidney produces a novel acylated peptide, ghrelin," FEBS Letters, vol. 486, no. 3, pp. 213-216, 2000.

[30] Y. Date, M. Nakazato, S. Hashiguchi et al., "Ghrelin is present in pancreatic $\alpha$-cells of humans and rats and stimulates insulin secretion," Diabetes, vol. 51, no. 1, pp. 124-129, 2002.

[31] Y. Date, N. Murakami, K. Toshinai et al., "The role of the gastric afferent vagal nerve in Ghrelin-induced feeding and growth hormone secretion in rats," Gastroenterology, vol. 123, no. 4, pp. 1120-1128, 2002.

[32] S. Gnanapavan, B. Kola, S. A. Bustin et al., "The tissue distribution of the mRNA of ghrelin and subtypes of its receptor, GHS-R, in humans," Journal of Clinical Endocrinology and Metabolism, vol. 87, no. 6, pp. 2988-2991, 2002.

[33] H. Ueno, H. Yamaguchi, K. Kangawa, and M. Nakazato, "Ghrelin: a gastric peptide that regulates food intake and energy homeostasis," Regulatory Peptides, vol. 126, no. 1-2, pp. 11-19, 2005.

[34] K. Matsuda, K. S. Kang, A. Sakashita, S. Yahashi, and H. Vaudry, "Behavioral effect of neuropeptides related to feeding regulation in fish," Annals of the New York Academy of Sciences, vol. 1220, no. 1, pp. 117-126, 2011.

[35] K. S. Kang, S. Yahashi, and K. Matsuda, "Central and peripheral effects of ghrelin on energy balance, food intake and lipid metabolism in teleost fish," Peptides, in press.

[36] S. P. Kalra, M. G. Dube, S. Pu, B. Xu, T. L. Horvath, and P. S. Kalra, "Interacting appetite-regulating pathways in the hypothalamic regulation of body weight," Endocrine Reviews, vol. 20, no. 1, pp. 68-100, 1999.

[37] T. Sakurai, "Roles of orexin/hypocretin in regulation of sleep/ wakefulness and energy homeostasis," Sleep Medicine Reviews, vol. 9, no. 4, pp. 231-241, 2005.

[38] C. Eva, A. Oberto, P. Mele, M. Serra, and G. Biggio, "Role of brain neuroactive steroids in the functional interplay between the GABAA and the NPY-Y1 receptor mediated signals in the amygdala," Pharmacology Biochemistry and Behavior, vol. 84, no. 4, pp. 568-580, 2006. 
[39] J. G. Pickar, J. M. Hill, and M. P. Kaufman, "Stimulation of vagal afferents inhibits locomotion in mesencephalic cats," Journal of Applied Physiology, vol. 74, no. 1, pp. 103-110, 1993.

[40] J. L. Nahon, "The melanocortins and melanin-concentrating hormone in the central regulation of feeding behavior and energy homeostasis," Comptes Rendus - Biologies, vol. 329, no. 8, pp. 623-638, 2006.

[41] J. E. Morley, M. Horowitz, P. M. K. Morley, and J. F. Flood, "Pituitary adenylate cyclase activating polypeptide (PACAP) reduces food intake in mice," Peptides, vol. 13, no. 6, pp. 1133$1135,1992$.

[42] D. Vaudry, B. J. Gonzalez, M. Basille, L. Yon, A. Fournier, and H. Vaudry, "Pituitary adenylate cyclase-activating polypeptide and its receptors: from structure to functions," Pharmacological Reviews, vol. 52, no. 2, pp. 269-324, 2000.

[43] L. De Groote, R. G. Peñalva, C. Flachskamm, J. M. H. M. Reul, and A. C. E. Linthorst, "Differential monoaminergic, neuroendocrine and behavioural responses after central administration of corticotropin-releasing factor receptor type 1 and type 2 agonists," Journal of Neurochemistry, vol. 94, no. 1, pp. 45-56, 2005.

[44] A. D. Howard, R. Wang, S. S. Pong et al., "Identification of receptors for neuromedin $\mathrm{U}$ and its role in feeding," Nature, vol. 406, no. 6791, pp. 70-74, 2000.

[45] J. Garcia de Mateos-Verchere, J. Leprince, M. C. Tonon, H. Vaudry, and J. Costentin, "The octadecaneuropeptide [diazepam-binding inhibitor (33-50)] exerts potent anorexigenic effects in rodents," European Journal of Pharmacology, vol. 414, no. 2-3, pp. 225-231, 2001.

[46] J. C. Do Rego, M. H. Orta, J. Leprince, M. C. Tonon, H. Vaudry, and J. Costentin, "Pharmacological characterization of the receptor mediating the anorexigenic action of the octadecaneuropeptide: evidence for an endozepinergic tone regulating food intake," Neuropsychopharmacology, vol. 32, no. 7, pp. 1641-1648, 2007.

[47] A. M. Wren and S. R. Bloom, "Gut hormones and appetite control," Gastroenterology, vol. 132, no. 6, pp. 2116-2130, 2007.

[48] P. Pusztai, B. Sarman, E. Ruzicska et al., "Ghrelin: a new peptide regulating the neurohormonal system, energy homeostasis and glucose metabolism," Diabetes/Metabolism Research and Reviews, vol. 24, no. 5, pp. 343-352, 2008.

[49] C. Diéguez, K. Da Boit, M. G. Novelle, P. B. Martínez De Morentin, R. Nogueiras, and M. López, "New insights in ghrelin orexigenic effect," Frontiers of Hormone Research, vol. 38, pp. 196-205, 2010.

[50] T. Miura, K. Maruyama, S. I. Shimakura et al., "Neuropeptide Y mediates ghrelin-induced feeding in the goldfish, Carassius auratus," Neuroscience Letters, vol. 407, no. 3, pp. 279-283, 2006.

[51] T. Miura, K. Maruyama, S. I. Shimakura et al., "Regulation of food intake in the goldfish by interaction between ghrelin and orexin," Peptides, vol. 28, no. 6, pp. 1207-1213, 2007.

[52] S. I. Shimakura, T. Miura, K. Maruyama et al., " $\alpha$-Melanocytestimulating hormone mediates melanin-concentrating hormone-induced anorexigenic action in goldfish," Hormones and Behavior, vol. 53, no. 2, pp. 323-328, 2008.

[53] T. Inhoff, H. Mönnikes, S. Noetzel et al., "Desacyl ghrelin inhibits the orexigenic effect of peripherally injected ghrelin in rats," Peptides, vol. 29, no. 12, pp. 2159-2168, 2008.

[54] G. J. Schwartz, "The role of gastrointestinal vagal afferents in the control of food intake: current prospects," Nutrition, vol. 16, no. 10, pp. 866-873, 2000.
[55] B. Kola, E. Hubina, S. A. Tucci et al., "Cannabinoids and ghrelin have both central and peripheral metabolic and cardiac effects via AMP-activated protein kinase," Journal of Biological Chemistry, vol. 280, no. 26, pp. 25196-25201, 2005.

[56] M. W. Sleeman and E. Latres, "The CAMplexities of central ghrelin,” Cell Metabolism, vol. 7, no. 5, pp. 361-362, 2008.

[57] J. S. Davies, P. Kotokorpi, S. R. Eccles et al., "Ghrelin induces abdominal obesity via GHS-R-dependent lipid retention," Molecular Endocrinology, vol. 23, no. 6, pp. 914-924, 2009.

[58] K. Matsuda, K. Wada, M. Azuma et al., "The octadecaneuropeptide exerts an anxiogenic-like action in goldfish," Neuroscience, vol. 181, pp. 100-108, 2011.

[59] S. Rotzinger, D. A. Lovejoy, and L. A. Tan, "Behavioral effects of neuropeptides in rodent models of depression and anxiety," Peptides, vol. 31, no. 4, pp. 736-756, 2010.

[60] M. Roy, N. K. David, J. V. Danao, H. Baribault, H. Tian, and M. Giorgetti, "Genetic inactivation of melanin-concentrating hormone receptor subtype I (MCHRI) in mice exerts anxiolytic-like behavioral effects," Neuropsychopharmacology, vol. 31, no. 1, pp. 112-120, 2006.

[61] D. Refojo and F. Holsboer, "CRH signaling: molecular specificity for drug targeting in the CNS," Annals of the New York Academy of Sciences, vol. 1179, pp. 106-119, 2009.

[62] D. M. Kokare, M. P. Dandekar, P. S. Singru, G. L. Gupta, and N. K. Subhedar, "Involvement of $\alpha$-MSH in the social isolation induced anxiety- and depression-like behaviors in rat," Neuropharmacology, vol. 58, no. 7, pp. 1009-1018, 2010.

[63] J. C. do Rego, J. Leprince, N. Chartrel, H. Vaudry, and J. Costentin, "Behavioral effects of 26RFamide and related peptides," Peptides, vol. 27, no. 11, pp. 2715-2721, 2006.

[64] J. A. Levine, N. L. Eberhardt, and M. D. Jensen, "Role of nonexercise activity thermogenesis in resistance to fat gain in humans," Science, vol. 283, no. 5399, pp. 212-214, 1999.

[65] T. Garland Jr., H. Schutz, M. A. Chappell et al., "The biological control of voluntary exercise, spontaneous physical activity and daily energy expenditure in relation to obesity: human and rodent perspectives," Journal of Experimental Biology, vol. 214, no. 2, pp. 206-229, 2011.

[66] M. Bourin, B. Petit-Demoulière, B. Nic Dhonnchadha, and M. Hascöet, "Animal models of anxiety in mice," Fundamental and Clinical Pharmacology, vol. 21, no. 6, pp. 567-574, 2007.

[67] M. Tang-Christensen, N. Vrang, S. Ortmann, M. Bidlingmaier, T. L. Horvath, and M. Tschöp, "Central administration of ghrelin and agouti-related protein (83-132) increases food intake and decreases spontaneous locomotor activity in rats," Endocrinology, vol. 145, no. 10, pp. 4645-4652, 2004.

[68] A. Yamanaka, C. T. Beuckmann, J. T. Willie et al., "Hypothalamic orexin neurons regulate arousal according to energy balance in mice," Neuron, vol. 38, no. 5, pp. 701-713, 2003.

[69] E. Jerlhag, "Systemic administration of ghrelin induces conditioned place preference and stimulates accumbal dopamine," Addiction Biology, vol. 13, no. 3-4, pp. 358-363, 2008.

[70] G. S. Barsh and M. W. Schwartz, "Genetic approaches to studying energy balance: perception and integration," Nature Reviews Genetics, vol. 3, no. 8, pp. 589-600, 2002.

[71] P. K. Thanos, M. Michaelides, C. W. Ho et al., "The effects of two highly selective dopamine $\mathrm{D}$ receptor antagonists (SB277011A and NGB-2904) on food self-administration in a rodent model of obesity," Pharmacology Biochemistry and Behavior, vol. 89, no. 4, pp. 499-507, 2008.

[72] G. Rizzolatti and G. Luppino, "The cortical motor system," Neuron, vol. 31, no. 6, pp. 889-901, 2001.

[73] A. Alachkar, J. M. Brotchie, and O. T. Jones, "Locomotor response to l-DOPA in reserpine-treated rats following central 
inhibition of aromatic 1-amino acid decarboxylase: further evidence for non-dopaminergic actions of 1-DOPA and its metabolites," Neuroscience Research, vol. 68, no. 1, pp. 44-50, 2010.

[74] T. Nakamura, K. Uramura, T. Nambu et al., "Orexin-induced hyperlocomotion and stereotypy are mediated by the dopaminergic system," Brain Research, vol. 873, no. 1, pp. 181187, 2000.

[75] K. Toshinai, Y. Date, N. Murakami et al., "Ghrelin-induced food intake is mediated via the orexin pathway," Endocrinology, vol. 144, no. 4, pp. 1506-1512, 2003.

[76] F. R. Faganello and R. Mattioli, "Anxiolytic-like effect of Chlorpheniramine in inhibitory avoidance in goldfish submitted to telencephalic ablation," Progress in Neuro-Psychopharmacology and Biological Psychiatry, vol. 31, no. 1, pp. 269-274, 2007.

[77] C. Maximino, T. Marques De Brito, C. A. G. De Mattos Dias, A. Gouveia, and S. Morato, "Scototaxis as anxiety-like behavior in fish," Nature Protocols, vol. 5, no. 2, pp. 209-216, 2010.

[78] J. C. Chuang and J. M. Zigman, "Ghrelin's roles in stress, mood, and anxiety regulation," International Journal of Peptides, vol. 2010, Article ID 460549, 5 pages, 2010.

[79] A. Asakawa, A. Inui, T. Kaga et al., "A role of ghrelin in neuroendocrine and behavioral responses to stress in mice," Neuroendocrinology, vol. 74, no. 3, pp. 143-147, 2001.

[80] E. Kristenssson, M. Sundqvist, M. Astin et al., "Acute psychological stress raises plasma ghrelin in the rat," Regulatory Peptides, vol. 134, no. 2-3, pp. 114-117, 2006.

[81] V. P. Carlini, M. M. Varas, A. B. Cragnolini, H. B. Schiöth, T. N. Scimonelli, and S. R. De Barioglio, "Differential role of the hippocampus, amygdala, and dorsal raphe nucleus in regulating feeding, memory, and anxiety-like behavioral responses to ghrelin," Biochemical and Biophysical Research Communications, vol. 313, no. 3, pp. 635-641, 2004.

[82] C. Aydin, O. Oztan, and C. Isgor, "Vulnerability to nicotine abstinence-related social anxiety-like behavior: molecular correlates in neuropeptide Y, Y2 receptor and corticotropin releasing factor," Neuroscience Letters, vol. 490, no. 3, pp. 220 225, 2011.

[83] E. Zambello, L. Zanetti, G. F. Hédou et al., "Neuropeptide YY2 receptor knockout mice: influence of genetic background on anxiety-related behaviors," Neuroscience, vol. 176, pp. 420430, 2011.

[84] A. Thorsell, "Brain neuropeptide Y and corticotropin-releasing hormone in mediating stress and anxiety," Experimental Biology and Medicine, vol. 235, no. 10, pp. 1163-1167, 2010.

[85] E. Painsipp, H. Herzog, and P. Holzer, "Implication of neuropeptide-Y Y2 receptors in the effects of immune stress on emotional, locomotor and social behavior of mice," Neuropharmacology, vol. 55, no. 1, pp. 117-126, 2008.

[86] R. O. Tasan, S. Lin, A. Hetzenauer, N. Singewald, H. Herzog, and G. Sperk, "Increased novelty-induced motor activity and reduced depression-like behavior in neuropeptide Y (NPY)Y4 receptor knockout mice," Neuroscience, vol. 158, no. 4, pp. 1717-1730, 2009. 

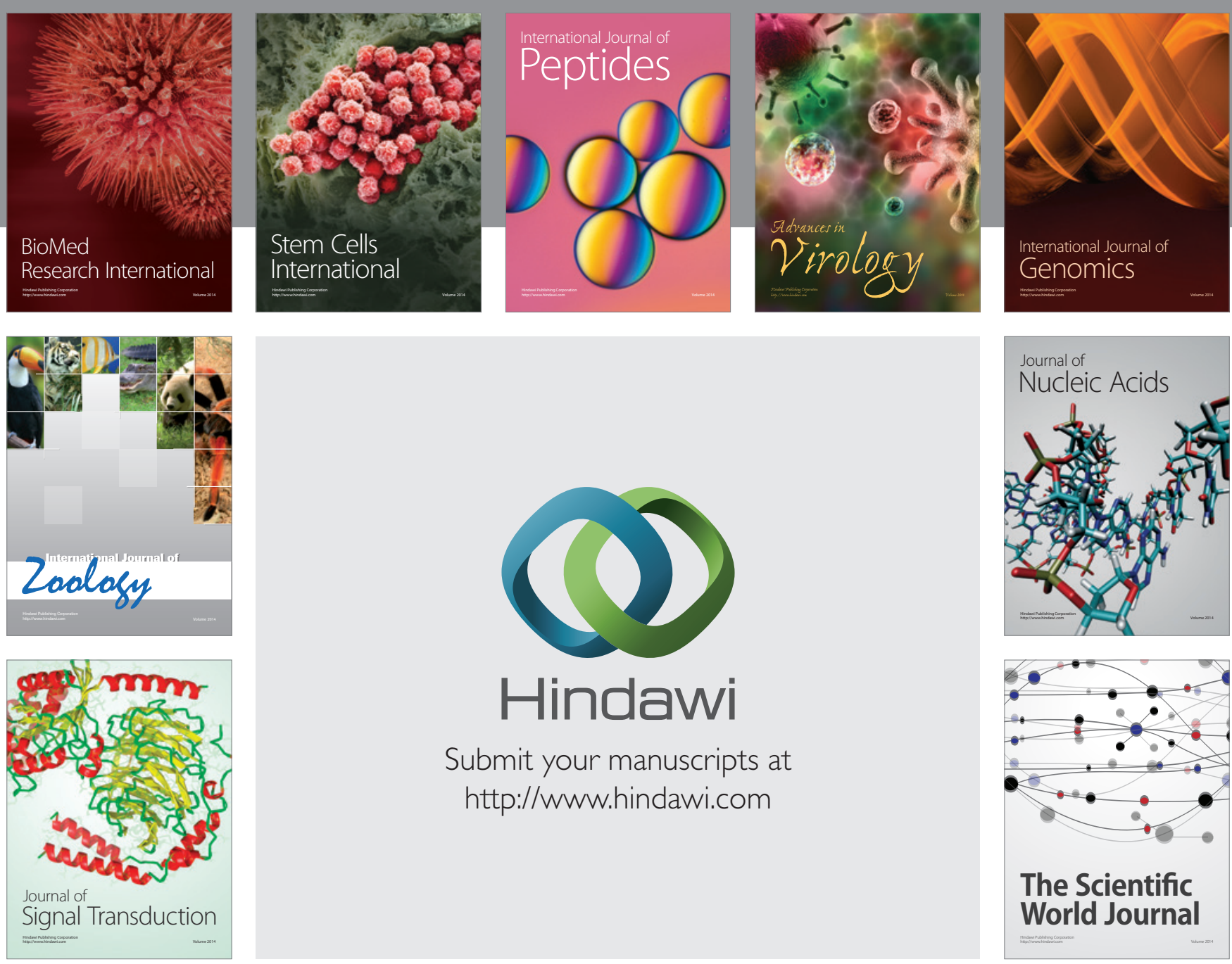

Submit your manuscripts at

http://www.hindawi.com
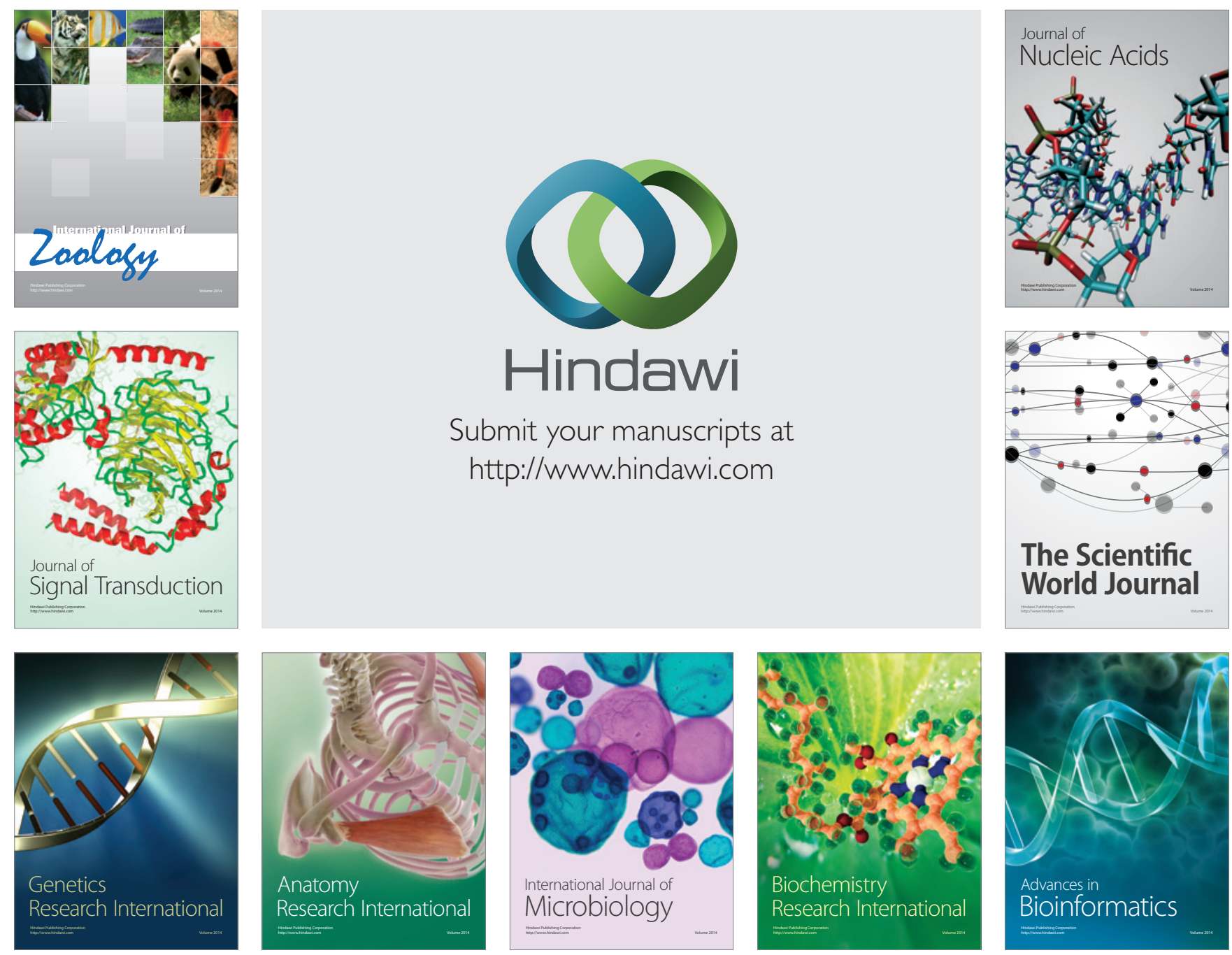

The Scientific World Journal
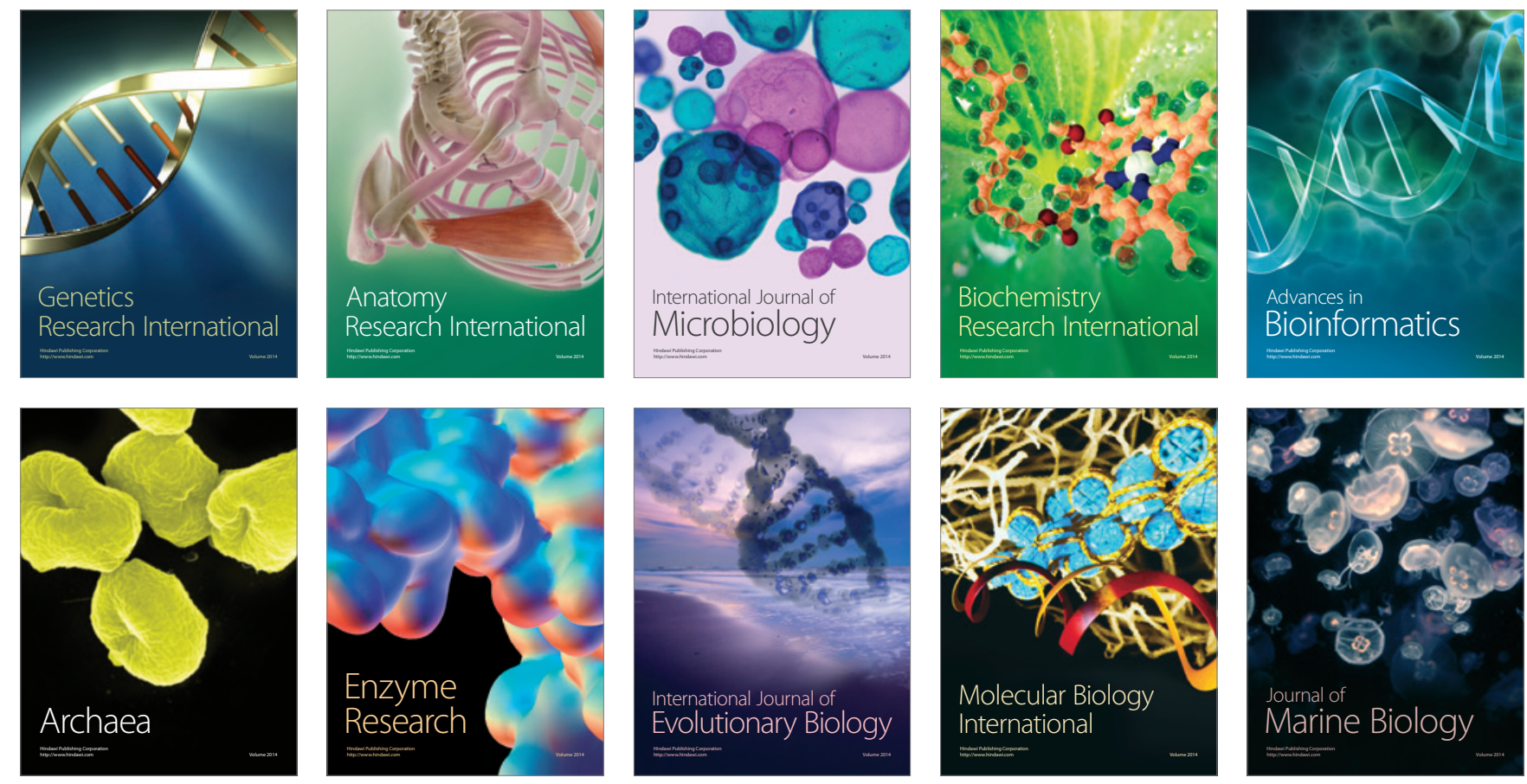